Supporting Information

\title{
Improving Charge Transfer in Metal-Organic Frameworks through Open Site Functionalization and Porosity Selection for Li-S Batteries
}

Bingqian Liu ${ }^{1}$ and V. Sara Thoi ${ }^{1,2^{*}}$

${ }^{1}$ Department of Chemistry, Johns Hopkins University, Baltimore, MD, 21218, United States

${ }^{2}$ Department of Materials Science and Engineering, Johns Hopkins University, Baltimore, MD, 21218, United States

Corresponding email: sarathoi@jhu.edu

\section{Table of Contents}

\section{Figures and Tables}

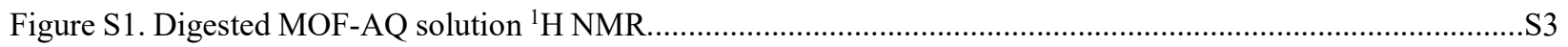

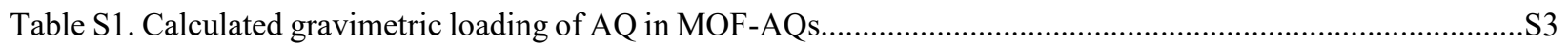

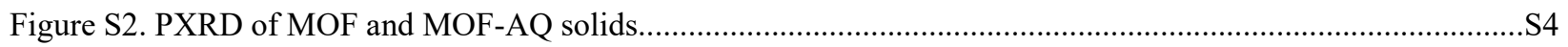

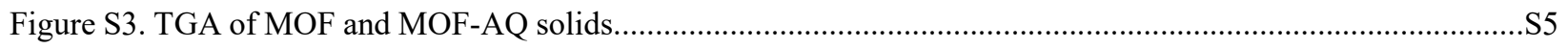

Table S2. BET surface area and pore volume of MOF and MOF-AQ solids.............................................................S6

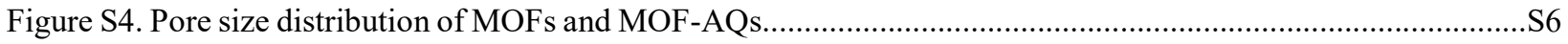

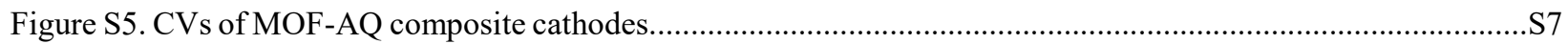

Figure S6. Photograph of polysulfide solution soaked with MOF.........................................................................

Figure S7. UV-vis spectra of polysulfide solution before and after MOF soaking..................................................S8

Figure S8. CVs of NU-1000+S and NU-1000-AQ+S composite cathodes...............................................................

Figure S9. Capacity retention of NU-1000+S and NU-1000-AQ+S composite cathodes..........................................S10

Figure S10. Galvanostatic cycling results of NU-1000-AQ composite cathodes without added S..............................S10

Figure S11. Galvanostatic charge-discharge profiles of NU-1000(-AQ)+S composites at various C rates.................S11

Figure S12. Normalized galvanostatic profiles of NU-1000(-AQ)+S composite cathodes.....................................S12

Table S3. $\Delta \mathrm{V}$ values of NU-1000(-AQ)+S composite cathodes at various $\mathrm{C}$ rates.................................................S12

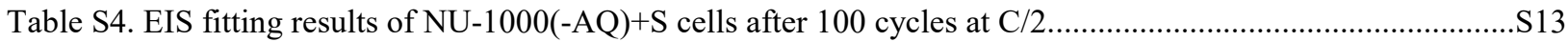

Figure S13. Nyquist plots of NU-1000(-AQ)+S cells after rate capability cycling.................................................. 13

Table S5. EIS fitting results of NU-1000(-AQ)+S cells after rate capability cycling.............................................S13 
Figure S14. Capacity retention of NU-1000-AQ+S and MOF-808-AQ+S composite cathodes.....

Figure S15-16. Galvanostatic profiles of NU-1000-AQ+S and MOF-808-AQ+S composites..... S15-16

Figure S17. Galvanostatic cycling results of $\mathrm{NU}-1000+\mathrm{S}$ and $\mathrm{MOF}-808+\mathrm{S}$ composites at various $\mathrm{C}$ rates. S17

Figure S18. CVs of MOF-808+S and MOF-808-AQ+S composite cathodes. S18

Figure S19. Normalized peak currents vs. square root of scan rate plot for MOF-808(-AQ)+S composites...........S18

Figure S20. Capacity retention of MOF-808+S and MOF-808-AQ+S composite cathodes. S19

Figure S21-22. Galvanostatic profiles of MOF-808(-AQ)+S composite cathodes at various $\mathrm{C}$ rates. S20-21

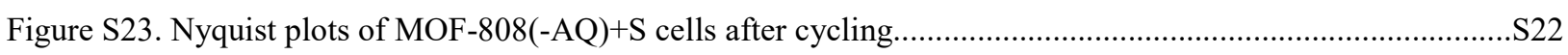

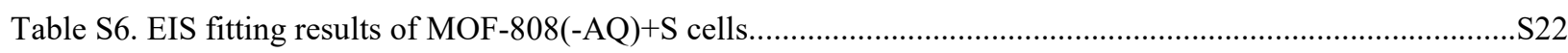

\section{References}




\section{Figures and Tables}
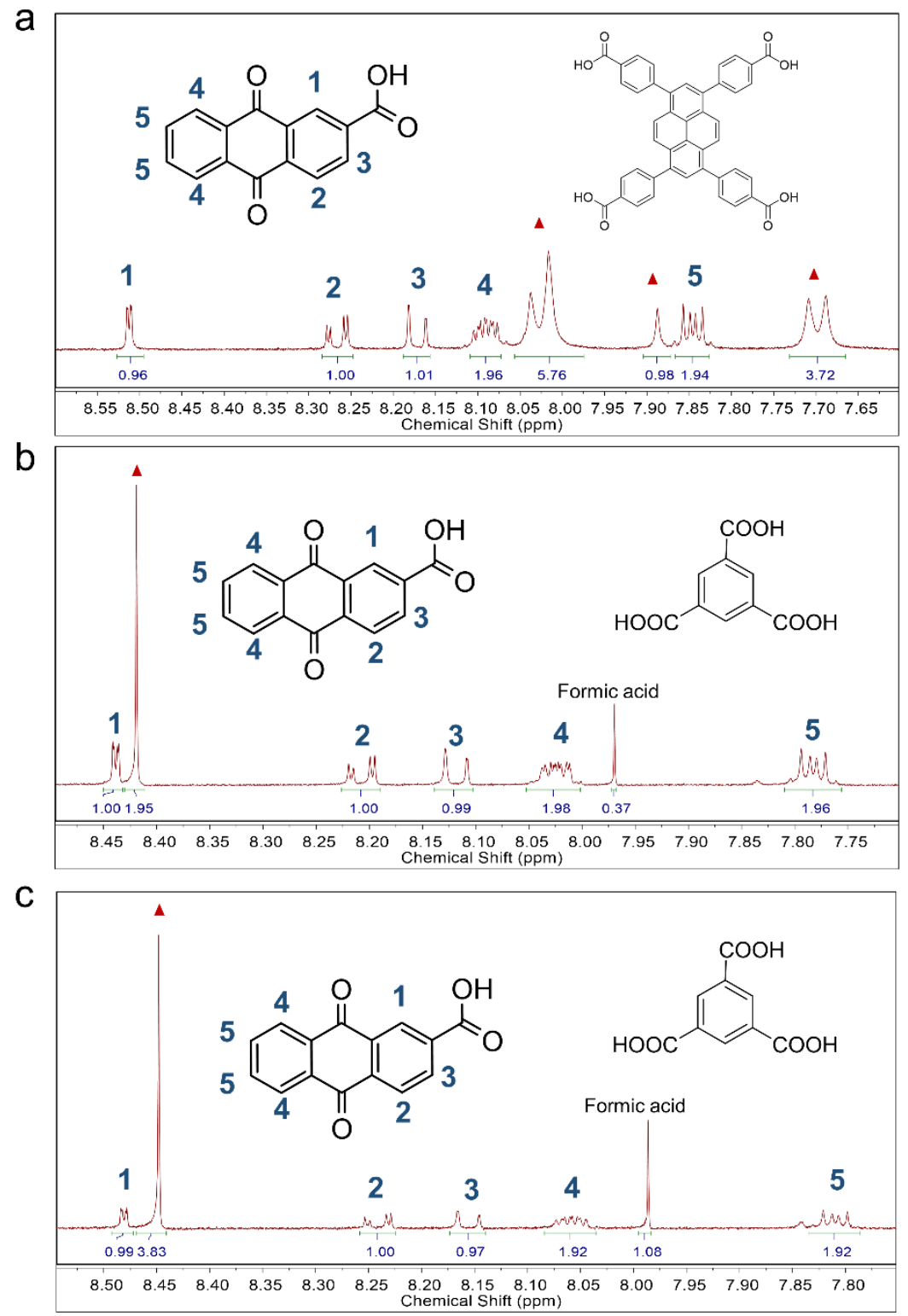

Figure S1. ${ }^{1} \mathrm{H}$ NMR spectra of digested (a) NU-1000-AQ, (b) MOF-808-3xAQ and (c) MOF-8081.5xAQ. Proton peaks corresponding to the ligands and anthraquinone carboxylic acid are labeled with red and blue, respectively. The AQ/ligand ratios are 2.06, 1.52, and 0.76 in NU-1000-AQ, MOF-808-3xAQ and MOF-808-1.5xAQ, respectively.

Table S1. The calculated gravimetric loading of AQ in MOF-AQ samples.

\begin{tabular}{|c|c|c|c|}
\hline & NU-1000-AQ & MOF-808-3xAQ & MOF-808-1.5xAQ \\
\hline Formula used for calculation & $\mathrm{Zr}_{6} \mathrm{O}_{4}(\mathrm{OH})_{4}(\mathrm{TBAPy})_{2}(\mathrm{AQ})_{4}$ & $\mathrm{Zr}_{6} \mathrm{O}_{4}(\mathrm{OH})_{4}(\mathrm{BTC})_{2}(\mathrm{AQ})_{3}(\mathrm{HCOO})_{3}$ & $\mathrm{Zr}_{6} \mathrm{O}_{4}(\mathrm{OH})_{4}(\mathrm{BTC})_{2}(\mathrm{AQ})_{1.5}(\mathrm{HCOO})_{4.5}$ \\
\hline wt\% AQ incorporated & 34.4 & 38.1 & 22.6 \\
\hline
\end{tabular}



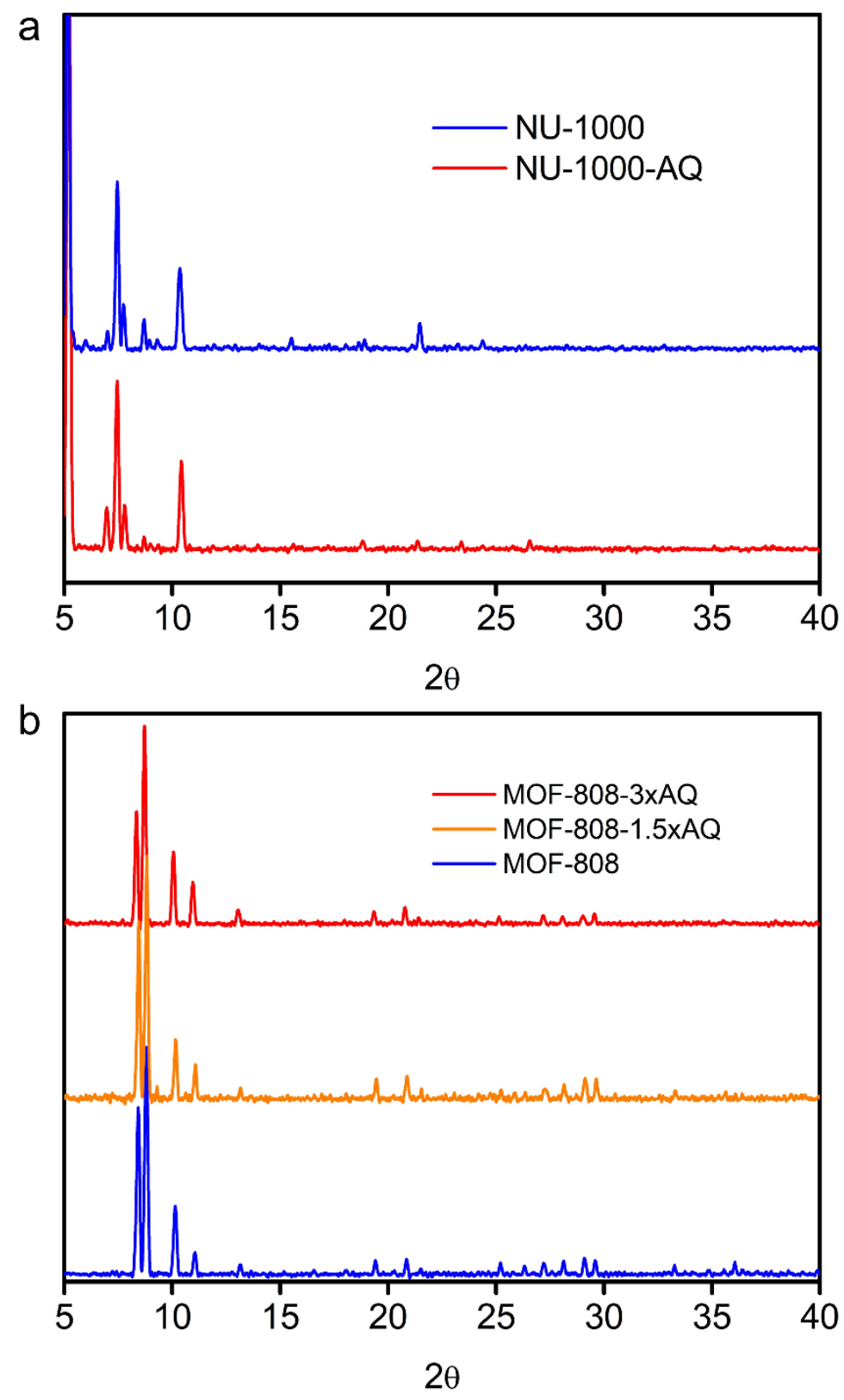

Figure S2. PXRD of (a) NU-1000 and (b) MOF-808 samples before and after AQ loading. 

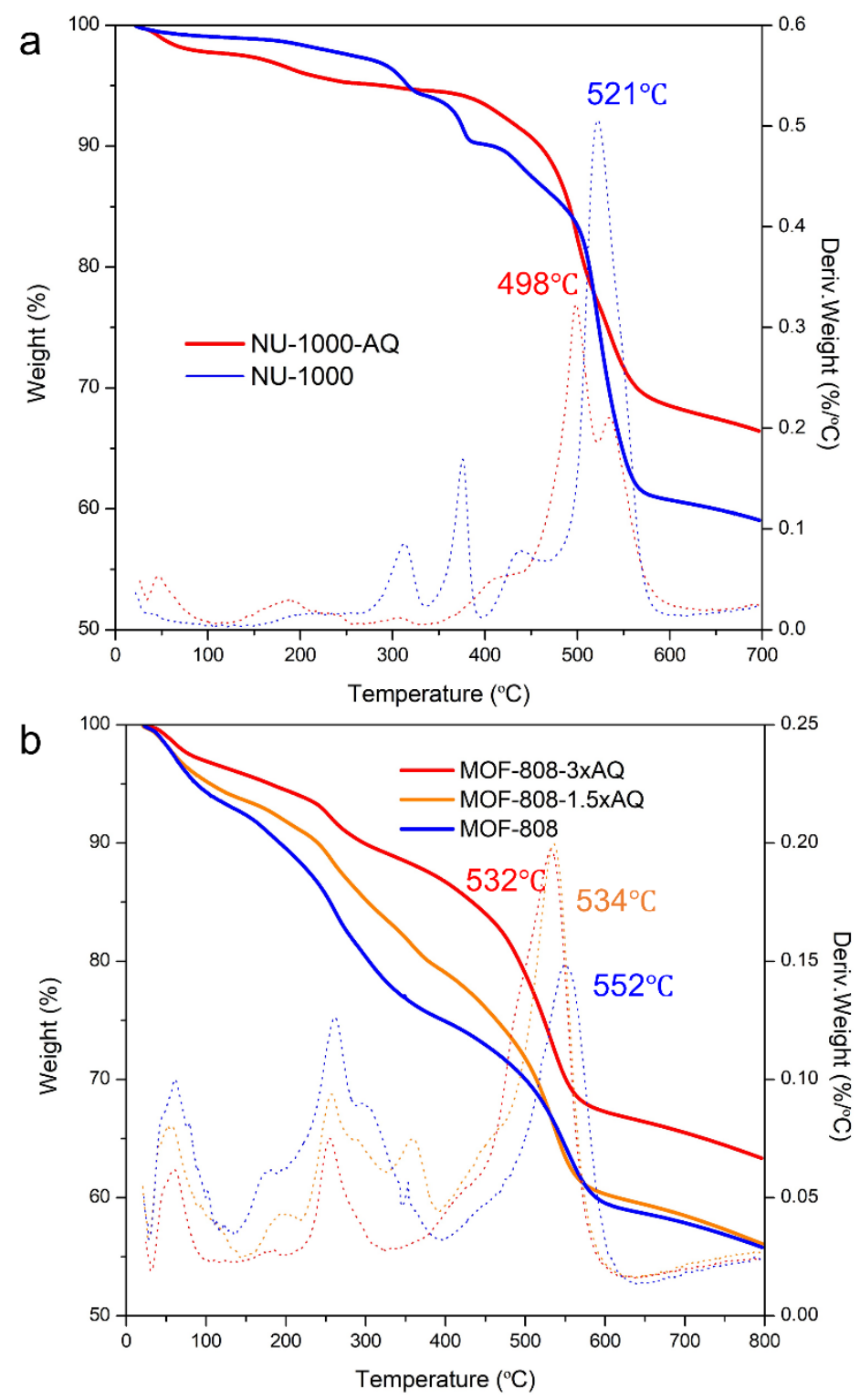

Figure S3. Thermogravimetric analysis of (a) NU-1000 \& NU-1000-AQ and (b) MOF-808 \& MOF-808-xAQ. 
Table S2. BET surface area and pore volume of MOF and MOF-AQ samples.

\begin{tabular}{|c|c|c|c|c|c|}
\hline & MOF-808 & MOF-808-1.5xAQ & MOF-808-3xAQ & NU-1000 & NU-1000-AQ \\
\hline Surface Area $\left(\mathrm{m}^{2} \mathrm{~g}^{-1}\right)$ & 1713.12 & 1374.75 & 811.26 & 2095.43 & 1376.18 \\
\hline Pore Volume $\left(\mathrm{cm}^{3} \mathrm{~g}^{-1}\right)$ & 0.685 & 0.561 & 0.316 & 1.394 & 0.854 \\
\hline
\end{tabular}
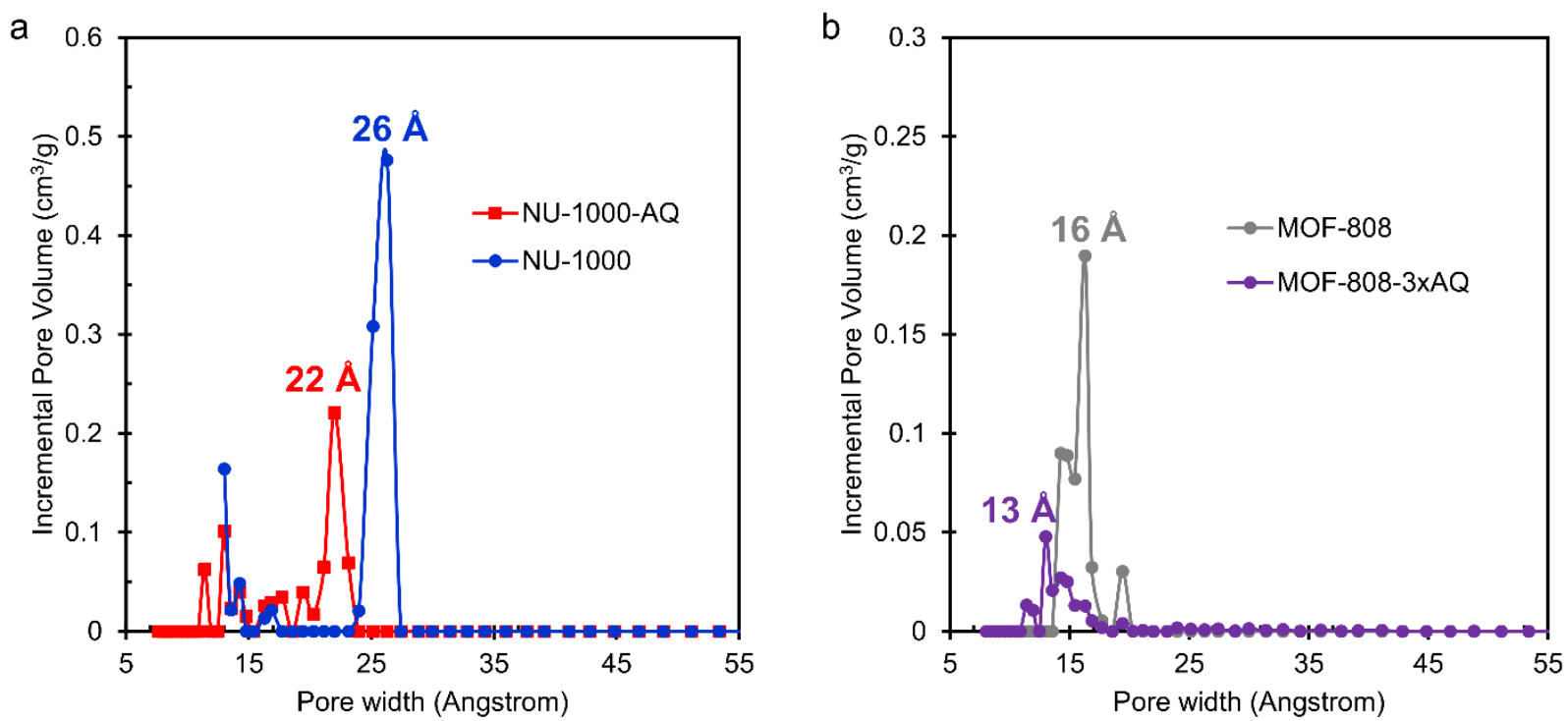

Figure S4. Pore size distribution of (a)NU-1000 \& NU-1000-AQ and (b) MOF-808 \& MOF-808$3 \times A Q$. 

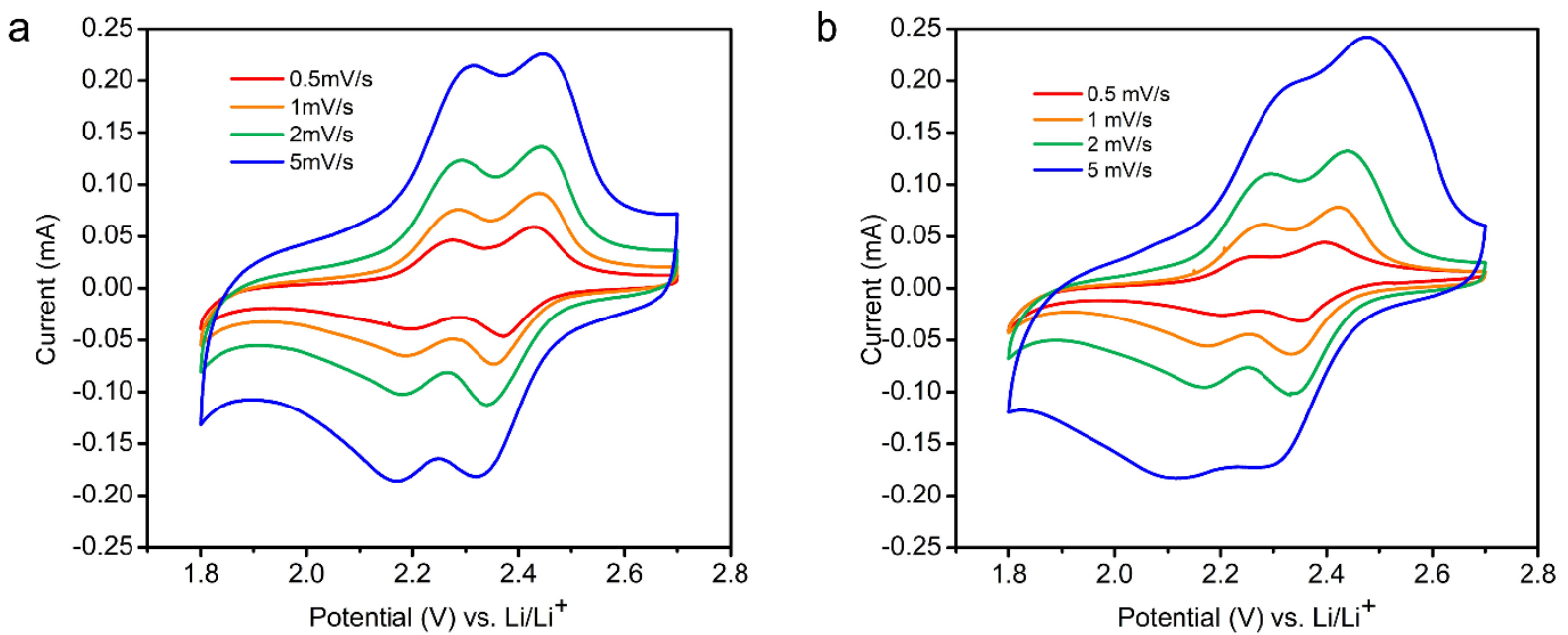

Figure S5. Cyclic voltammograms of coin cells constructed with (a) NU-1000-AQ and (b)MOF808-3xAQ composite cathodes. The cells were cycled between $1.8 \mathrm{~V}$ and $2.7 \mathrm{~V}\left(\mathrm{vs} . \mathrm{Li} / \mathrm{Li}^{+}\right)$at various scan rates. 

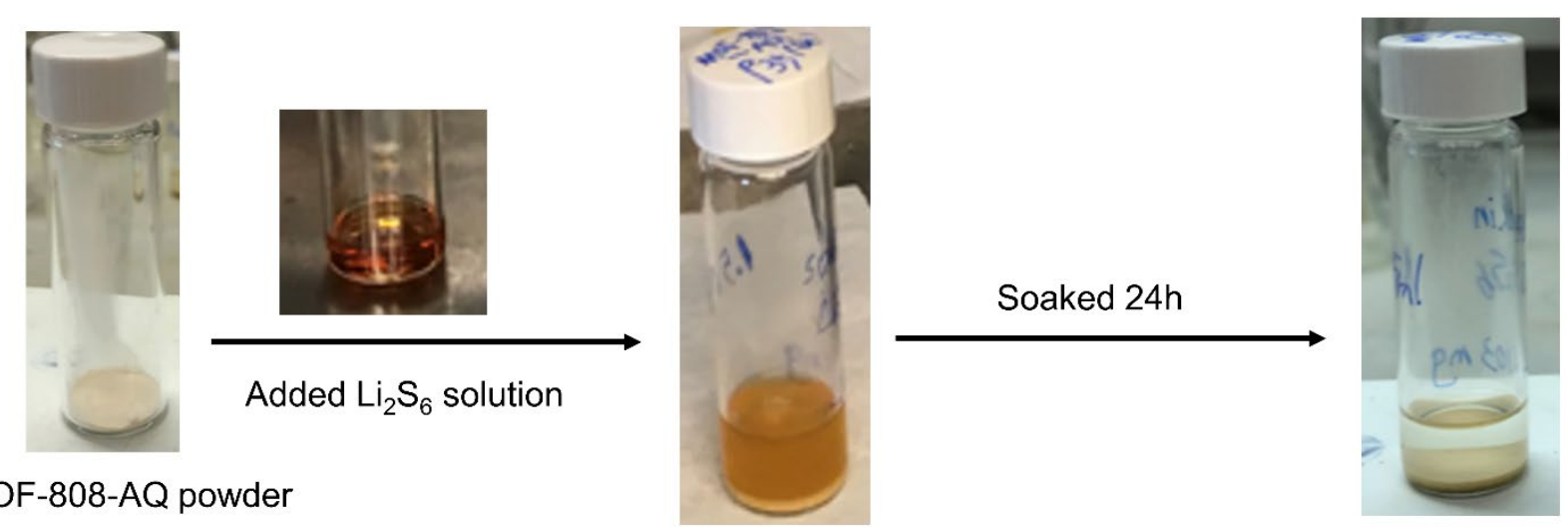

MOF-808-AQ powder

Added $\mathrm{Li}_{2} \mathrm{~S}_{6}$ solution

Figure S6. MOF-808-AQ powder was soaked in $\mathrm{Li}_{2} \mathrm{~S}_{6}$ solution for $24 \mathrm{~h}$. The color of the solution turned from orange to transparent after soaking. The color change implies the polysulfides have diffused into the MOF pores.

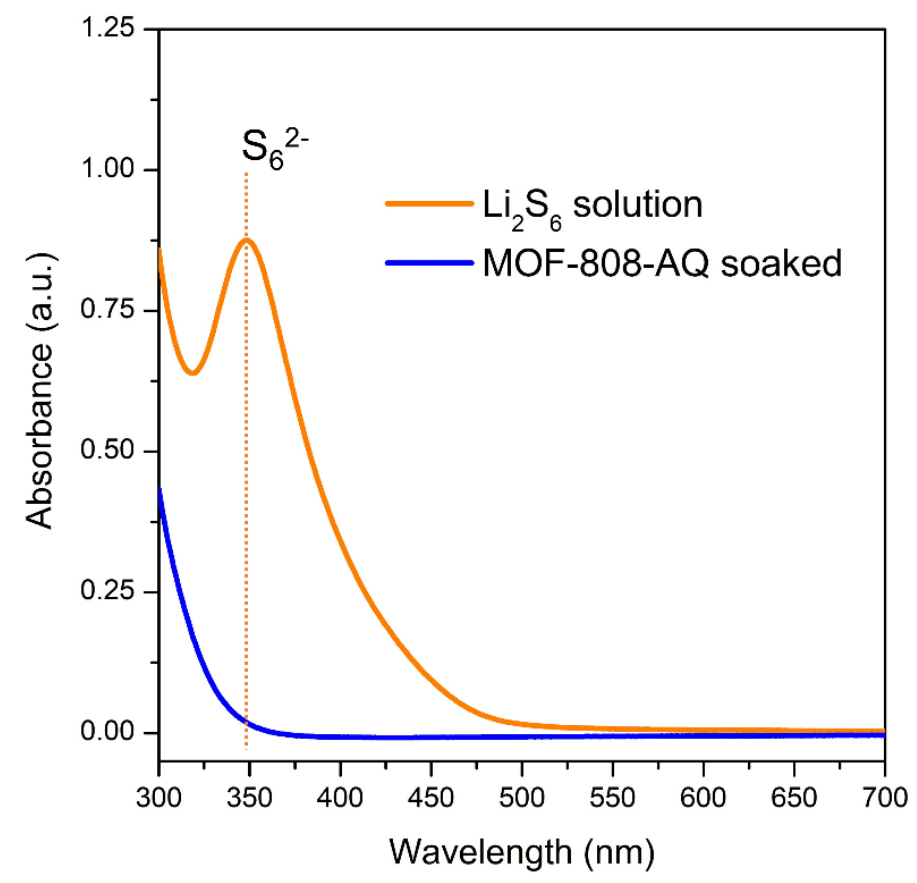

Figure S7. UV-vis spectra of $\mathrm{Li}_{2} \mathrm{~S}_{6}$ solution before and after soaking with MOF-808-AQ powder. The absence of peak around $350 \mathrm{~nm}$ (assigned to $\left.\mathrm{S}_{6}{ }^{2-}\right)^{1,2}$ demonstrates that MOF samples have the ability to uptake lithium polysulfides from solution. 
a

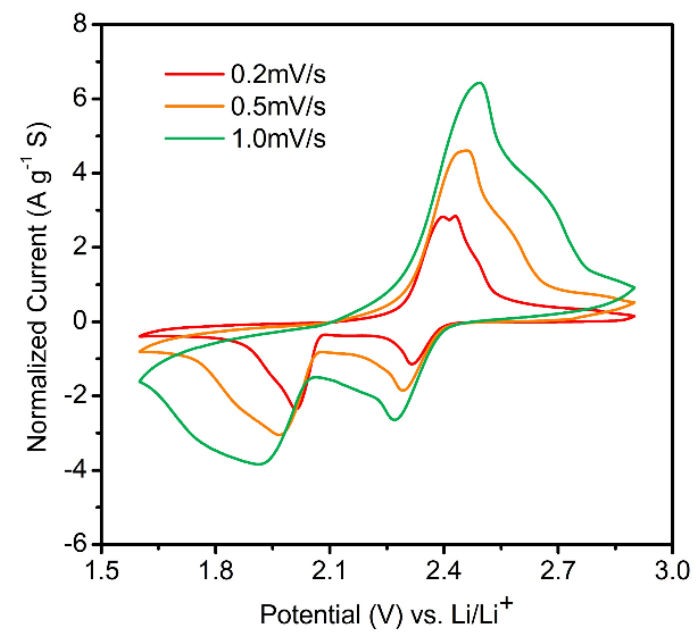

b

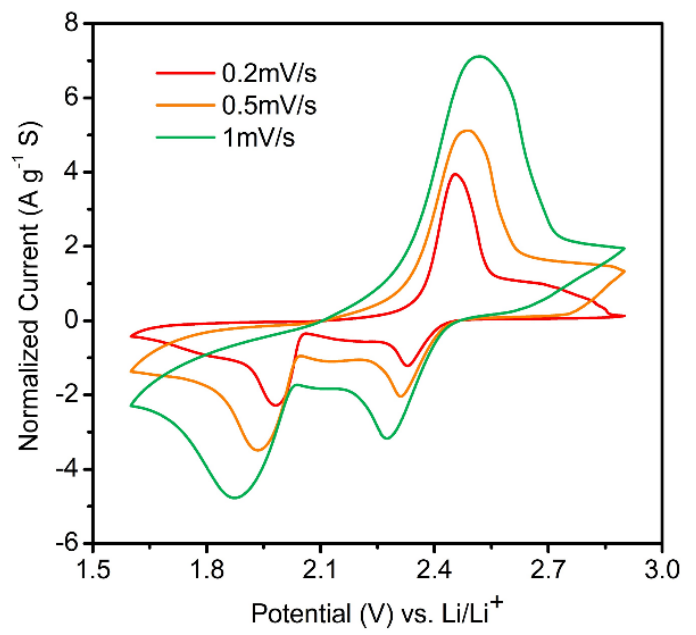

Figure S8. Cyclic voltammograms of coin cells constructed with (a) NU-1000+S and (b) NU1000-AQ $+\mathrm{S}$ composite cathodes. The cells were cycled between $1.6 \mathrm{~V}$ and $2.9 \mathrm{~V}\left(\mathrm{vs} . \mathrm{Li} / \mathrm{Li}^{+}\right)$at various scan rates. 


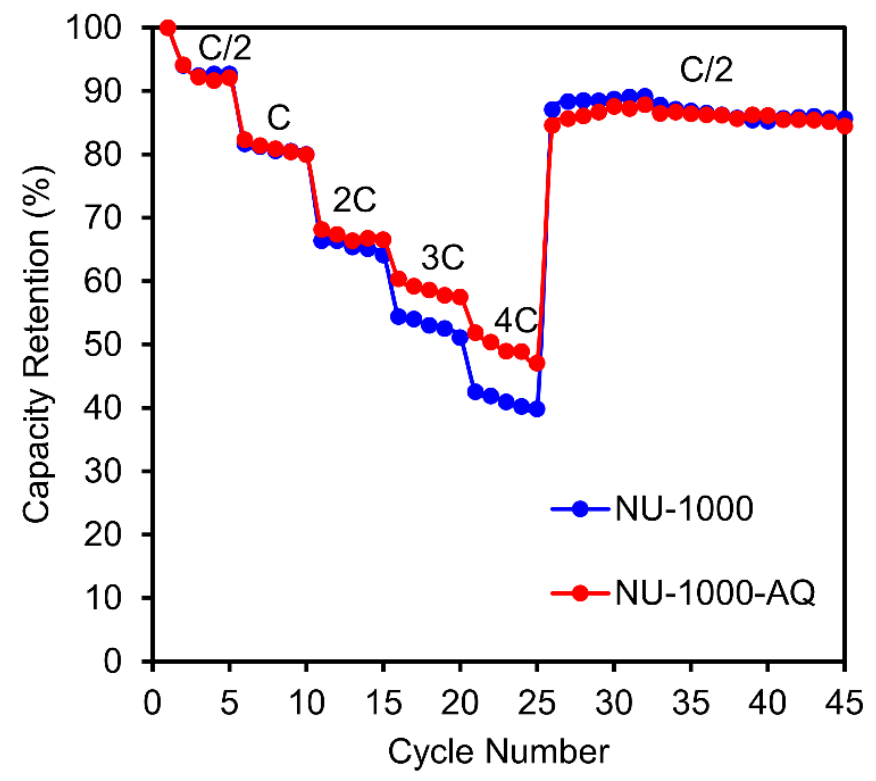

Figure S9. Capacity retention of NU-1000+S and NU-1000-AQ+S composite electrodes at different $\mathrm{C}$-rates, showing improved performance of AQ loaded MOFs.

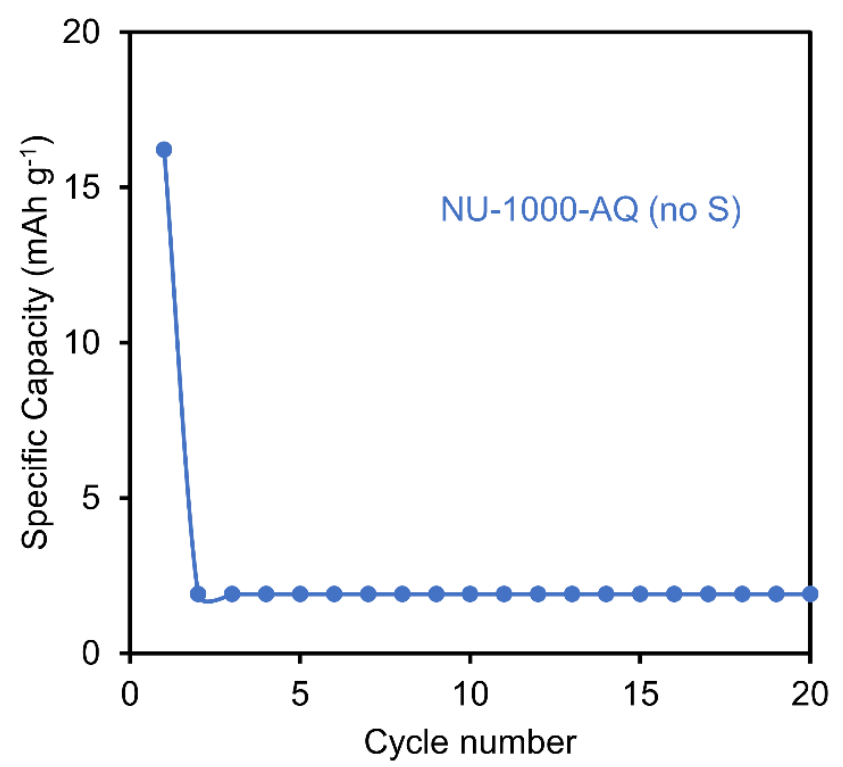

Figure S10. Galvanostatic cycling results for coin cells prepared with NU-1000-AQ without added S. The cathode slurry consists of 30\% NU-1000-AQ, 50\% Super-P carbon and 20\% PVDF. The cell was cycled at $\mathrm{C} / 10$ at the first cycle, followed by 20 cycles at $\mathrm{C} / 2$. The mass used to calculate specific capacity and current applied to the cell was $45 \%$ of the total mass of dried cathode material coated on carbon paper. NU-1000-AQ host only provide negligible contribution to the capacity. 

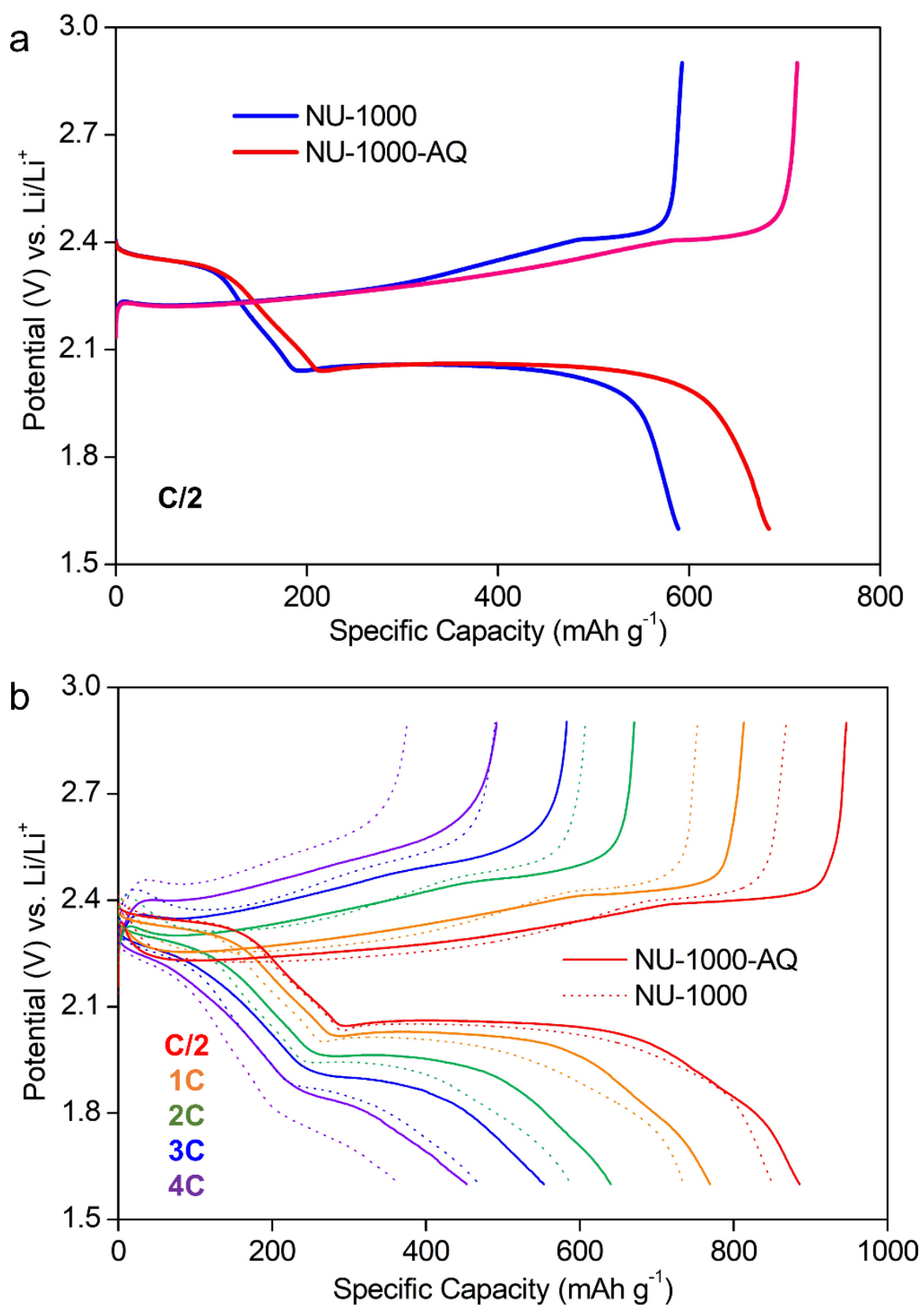

Figure S11. (a) Overlaid galvanostatic charge-discharge profiles for NU-1000+S and NU-1000$\mathrm{AQ}+\mathrm{S}$ at $\mathrm{C} / 2\left(100^{\text {th }}\right.$ cycle). (b) Overlaid galvanostatic charge-discharge profiles for $\mathrm{NU}-1000+\mathrm{S}$ and NU-1000-AQ+S of rate capability cycling, at the last cycle of $\mathrm{C} / 2,1 \mathrm{C}, 2 \mathrm{C}, 3 \mathrm{C}$, and $4 \mathrm{C}$. 

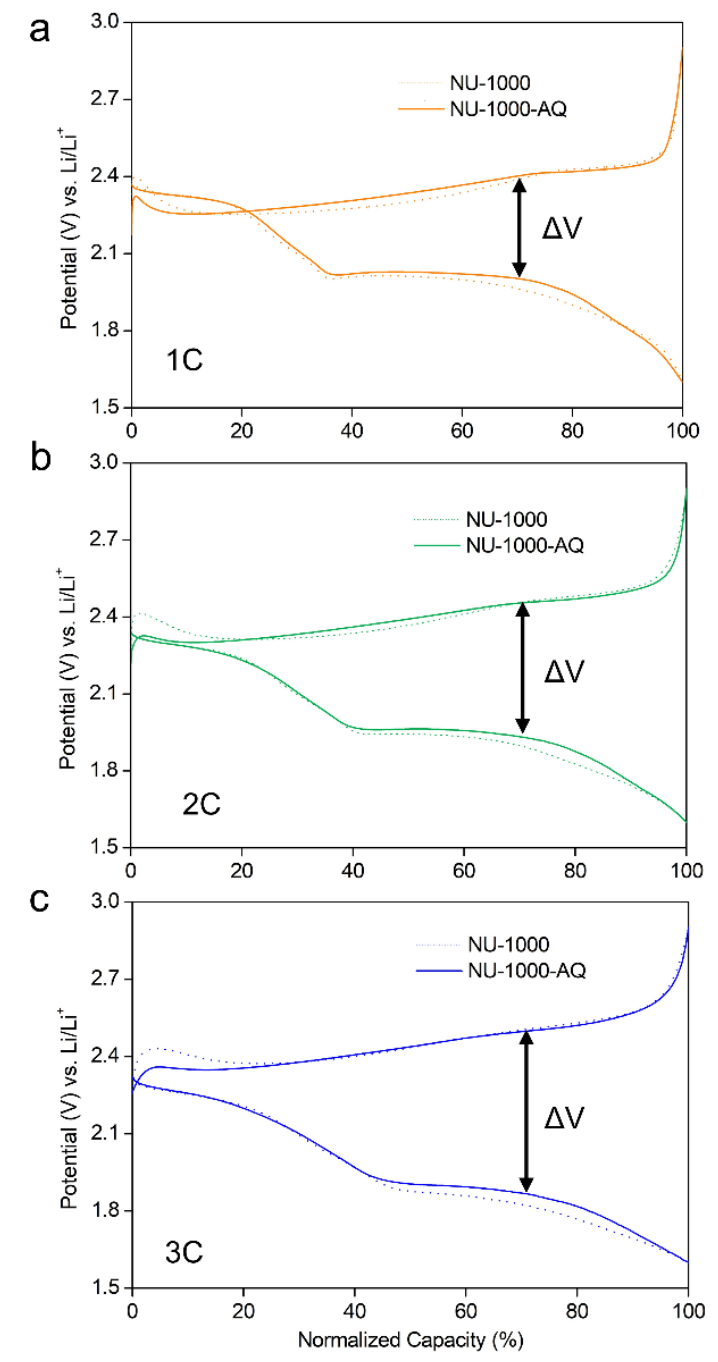

Figure S12. Normalized galvanostatic charge-discharge profiles for NU-1000 (dot line) and NU1000-AQ (solid line) at (1) 1C, (b) 2C, and (c) 3C. NU-1000-AQ exhibit a smaller $\Delta \mathrm{V}$ and more defined second plateau starting from 2C compared to NU-1000, suggesting AQ functionalization can facilitate polysulfide equilibria and reduce the overpotential for fast charge and discharge.

Table S3. $\Delta$ V values (unit: V) of NU-1000+S and NU-1000-AQ+S cells at various $\mathrm{C}$ rates. (at the normalized capacity of $60 \%$ )

\begin{tabular}{|c|c|c|c|c|c|}
\hline & C/2 & C & 2C & 3C & 4C \\
\hline NU-1000 & 0.262 & 0.340 & 0.479 & 0.614 & 0.741 \\
\hline NU-1000-AQ & 0.266 & 0.345 & 0.468 & 0.578 & 0.669 \\
\hline
\end{tabular}


Table S4. EIS fitting results collected on coin cells after 100 cycles at $\mathrm{C} / 2$ in the discharged state.

\begin{tabular}{|c|c|c|c|c|}
\hline & $\mathbf{R}_{\mathbf{1}}(\boldsymbol{\Omega})$ & $\mathbf{R}_{\mathbf{2}}(\boldsymbol{\Omega})$ & $\mathbf{R}_{\mathbf{3}}(\boldsymbol{\Omega})$ & $\mathbf{W} \times \mathbf{1 0}^{-\mathbf{2}}\left(\boldsymbol{\Omega} \mathbf{~ s}^{-1 / 2}\right)$ \\
\hline $\mathrm{NU}-1000$ & 6.21 & 19.53 & 33.51 & 4.27 \\
\hline NU-1000-AQ & 7.67 & 8.35 & 17.23 & 4.21 \\
\hline
\end{tabular}

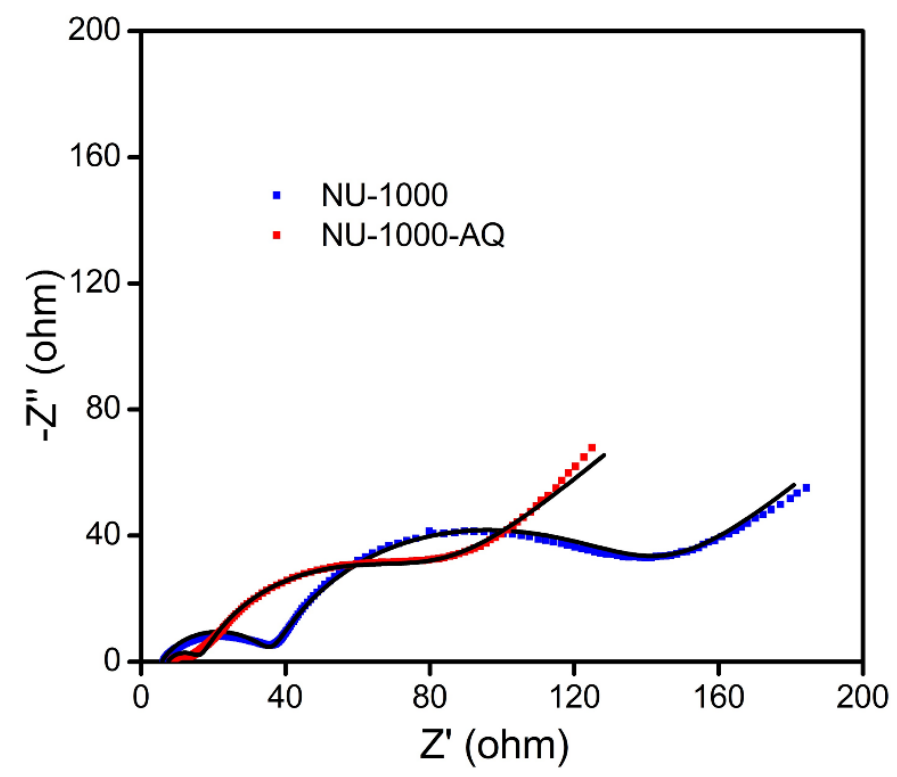

Figure S13. EIS and fitting curves (black line) collected on coin cells after rate capability test in the discharged state.

Table S5. EIS fitting results collected on coin cells after rate capability test in the discharged state.

\begin{tabular}{|c|c|c|c|c|}
\hline & $\mathbf{R}_{\mathbf{1}}(\boldsymbol{\Omega})$ & $\mathbf{R}_{\mathbf{2}}(\boldsymbol{\Omega})$ & $\mathbf{R}_{\mathbf{3}}(\boldsymbol{\Omega})$ & $\mathbf{W} \times \mathbf{1 0}^{-\mathbf{2}}\left(\boldsymbol{\Omega} \mathbf{~ s}^{-1 / 2}\right)$ \\
\hline $\mathrm{NU}-1000$ & 5.68 & 30.25 & 92.93 & 5.32 \\
\hline $\mathrm{NU}-1000-\mathrm{AQ}$ & 7.40 & 8.44 & 49.53 & 2.71 \\
\hline
\end{tabular}




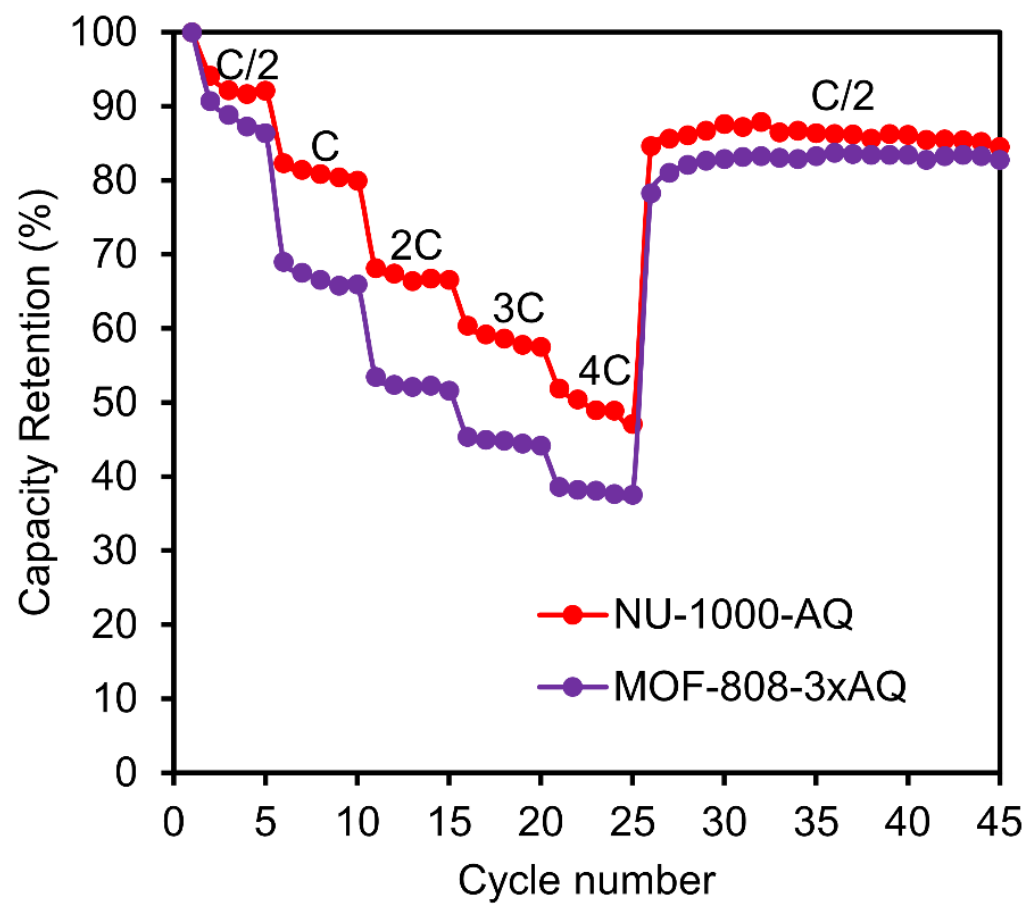

Figure S14. Capacity retention of NU-1000-AQ+S and MOF-808-3xAQ+S composite electrodes at various $\mathrm{C}$-rates. 

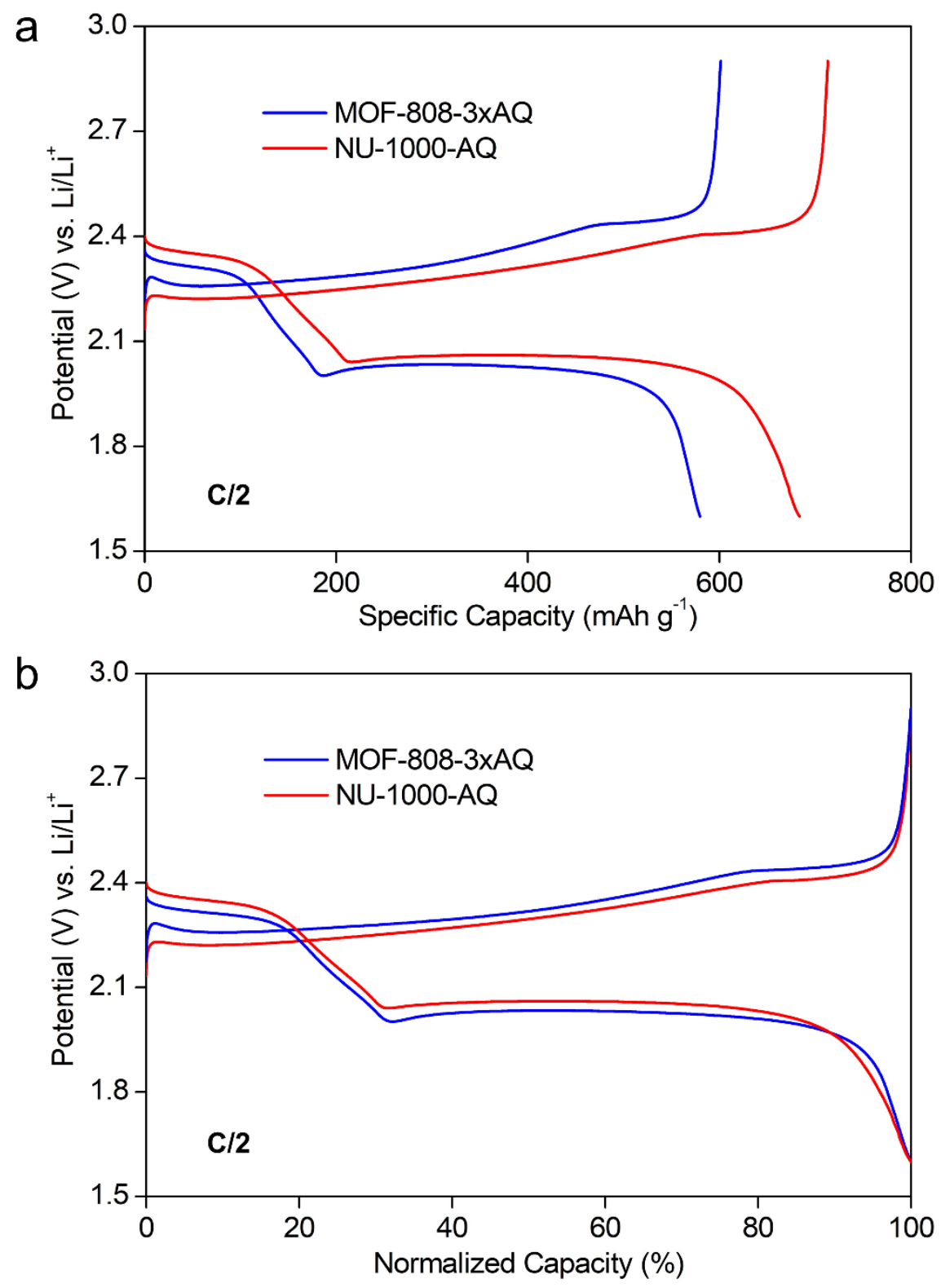

Figure S15. Overlaid galvanostatic charge-discharge profiles for NU-1000-AQ and MOF-808$3 x A Q$ at $C / 2\left(100^{\text {th }}\right.$ cycle $)$. 

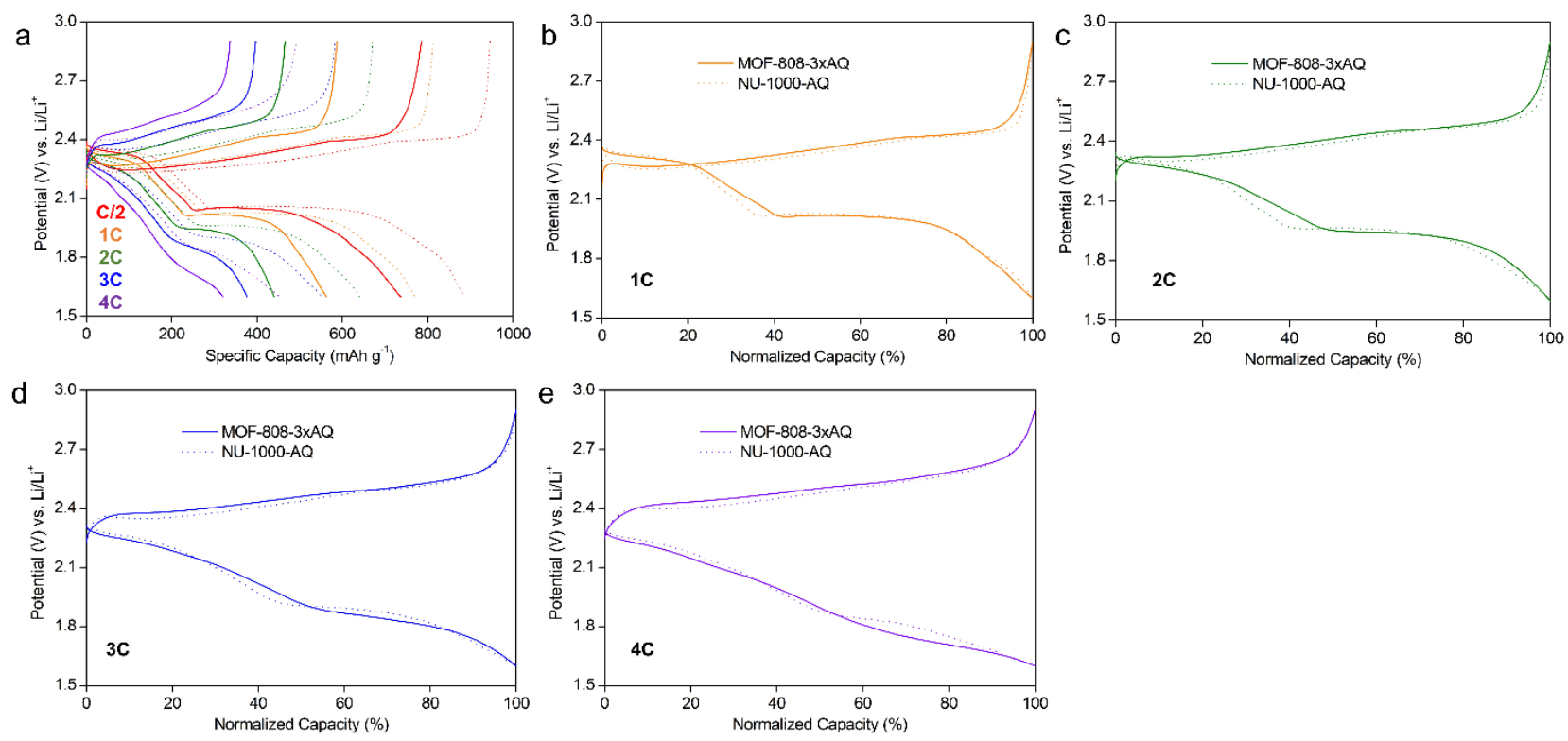

Figure S16. Overlaid galvanostatic charge-discharge profiles for NU-1000-AQ (dot line) and MOF-808-3xAQ (solid line) at different $\mathrm{C}$ rates. 

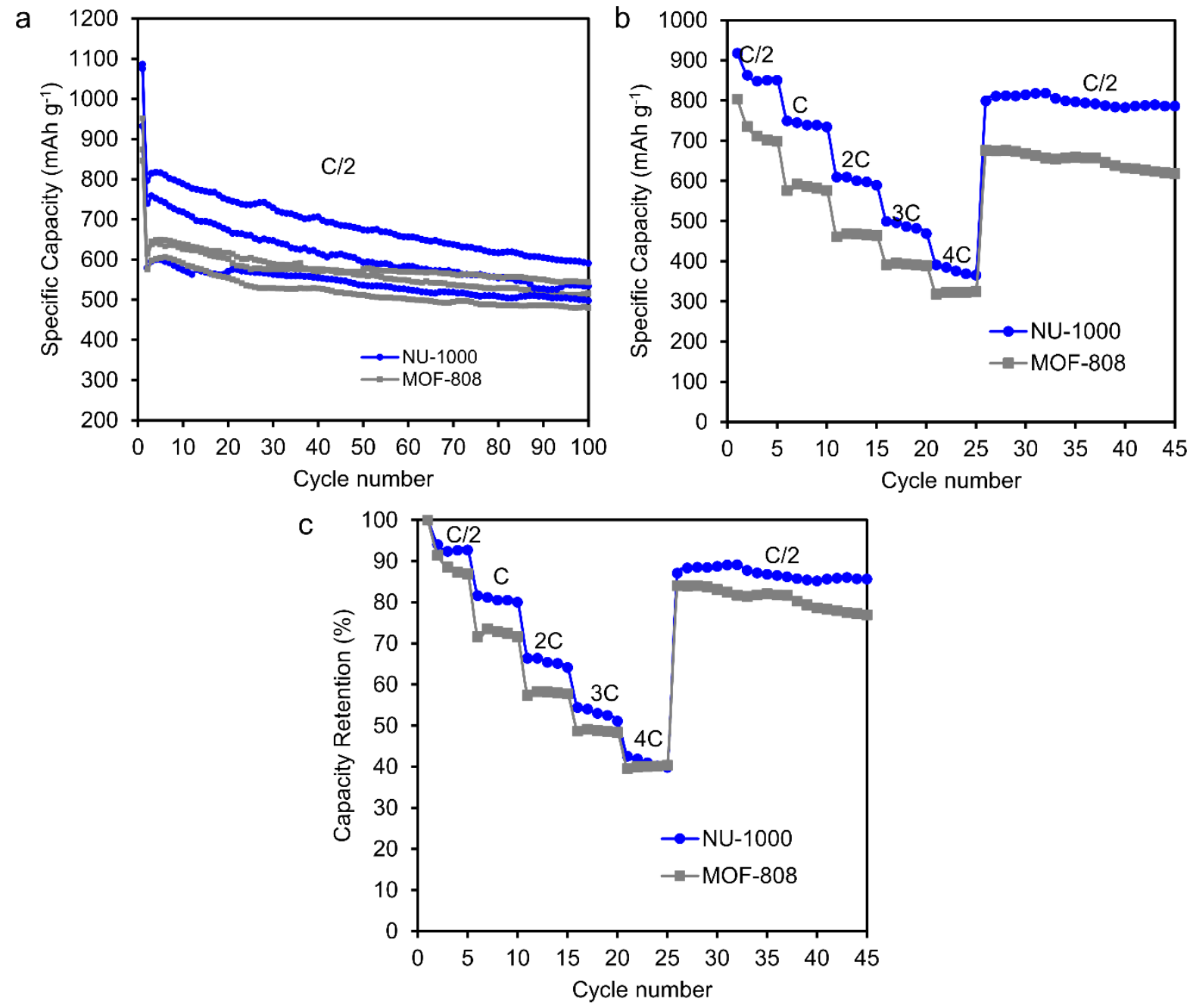

Figure S17. Galvanostatic cycling results for NU-1000+S and MOF-808+S composite electrodes at different C-rates with (a,b) specific capacity and (c) capacity retention as y axis. 

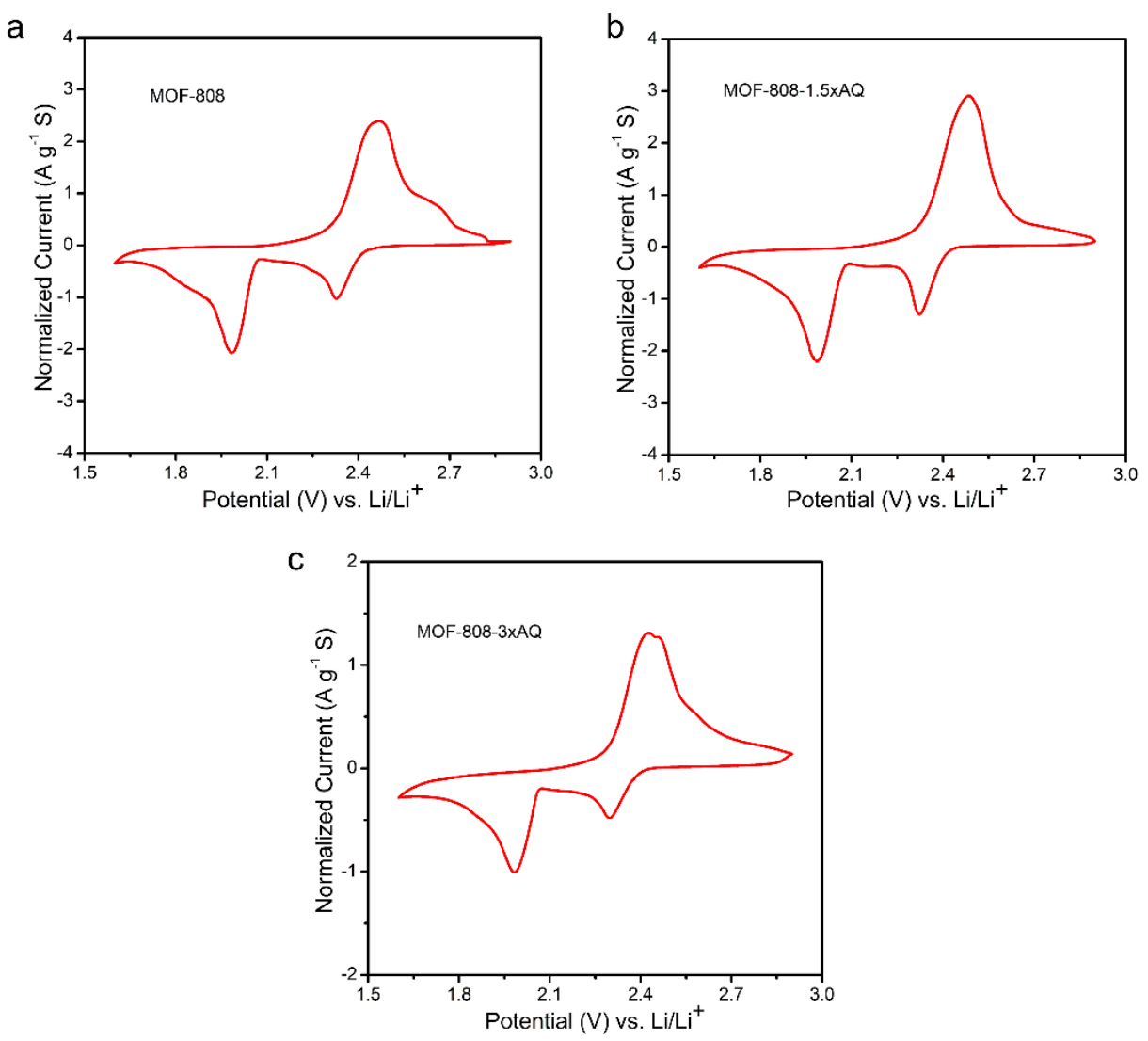

Figure S18. Cyclic voltammograms of coin cells constructed with (a) MOF-808+S, (b) MOF-808$1.5 \times A Q+S$ and (c) MOF-808-3xAQ+S composite cathodes. The cells were cycled between $1.6 \mathrm{~V}$ and $2.9 \mathrm{~V}\left(\mathrm{vs} . \mathrm{Li} / \mathrm{Li}^{+}\right)$at the scan rate of $0.2 \mathrm{mV} / \mathrm{s}$. All composites show the typical two cathodic events at $\sim 2.3 \mathrm{~V}$ and $\sim 2.0 \mathrm{~V}$ and one broad anodic event.
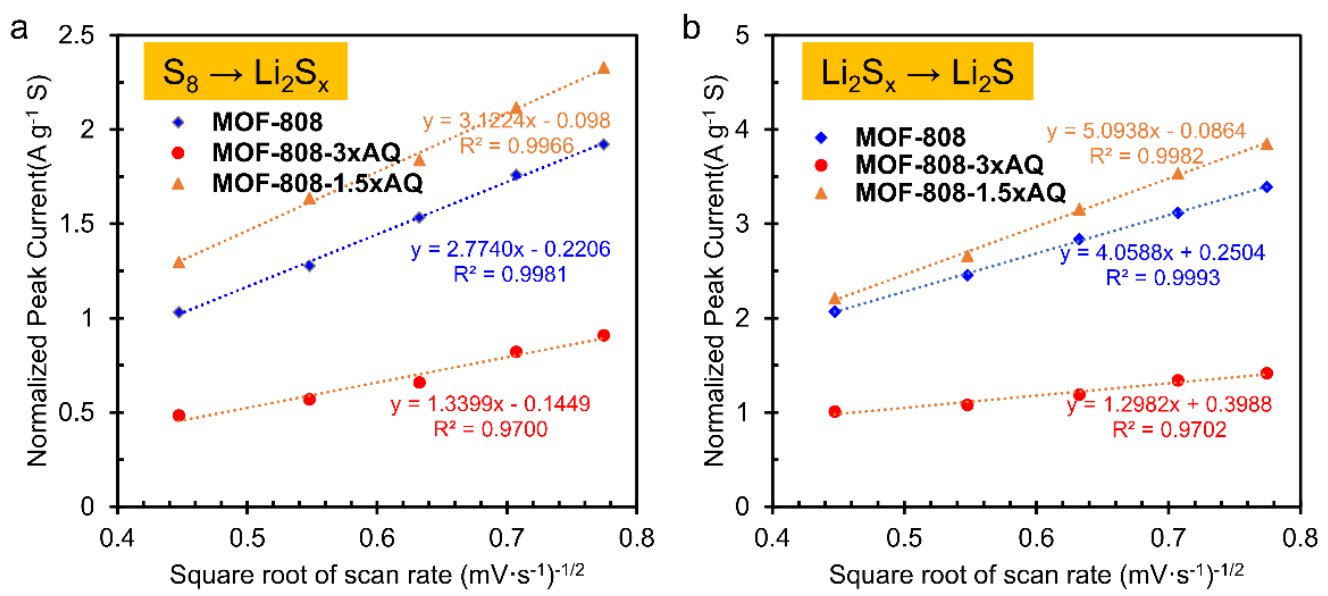

Figure S19. The linear fit of normalized peak currents on square root of scan rates for MOF808+S and MOF-808-xAQ+S composites in (a) $\mathrm{S}_{8}$ to $\mathrm{Li}_{2} \mathrm{~S}_{\mathrm{x}}$, (b) $\mathrm{Li}_{2} \mathrm{~S}_{\mathrm{x}}$ to $\mathrm{Li}_{2} \mathrm{~S}$ step. 


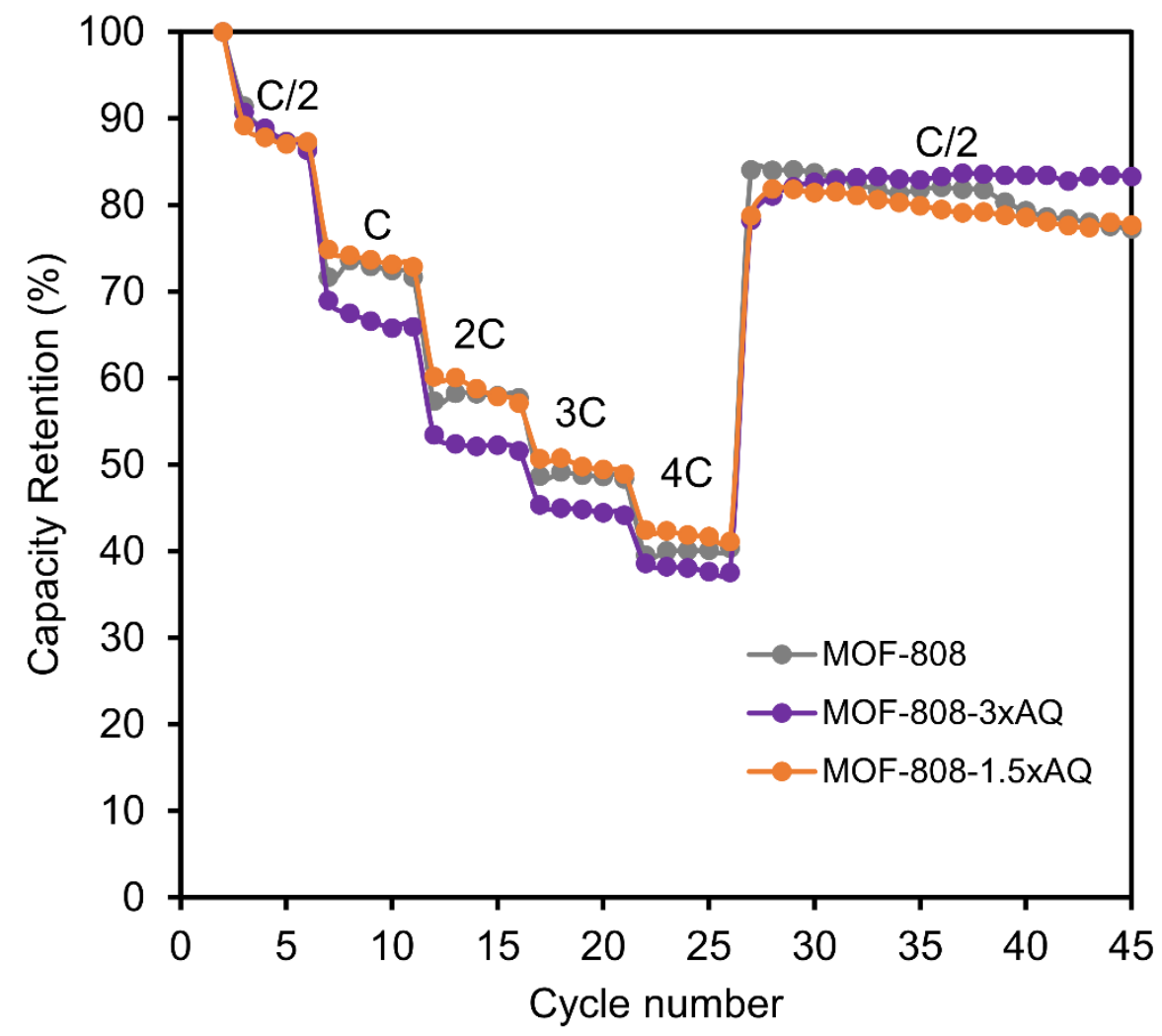

Figure S20. Capacity retention of MOF-808+S and MOF-808-xAQ+S composite electrodes from moderate $\mathrm{C}$-rates to high $\mathrm{C}$-rates. 

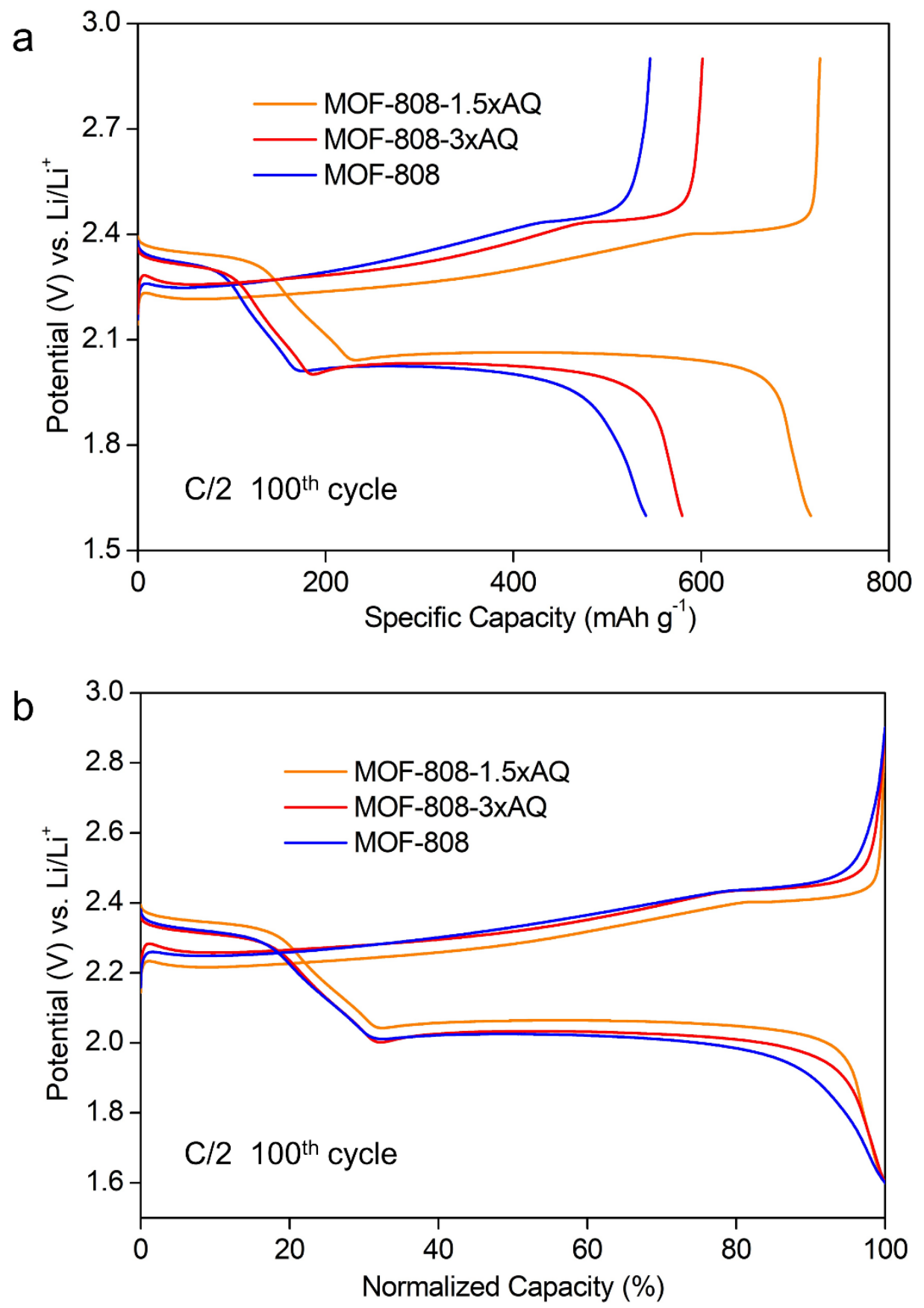

Figure S21. Overlaid galvanostatic charge-discharge profiles for MOF-808, MOF-808-1.5xAQ and MOF-808-3xAQ at $\mathrm{C} / 2\left(100^{\text {th }}\right.$ cycle) with (a) specific capacity and (b) normalized capacity as $\mathrm{x}$ axis. MOF-808-1.5xAQ shows smaller $\Delta \mathrm{V}$, suggesting enhanced PS equilibrium and diffusion. 

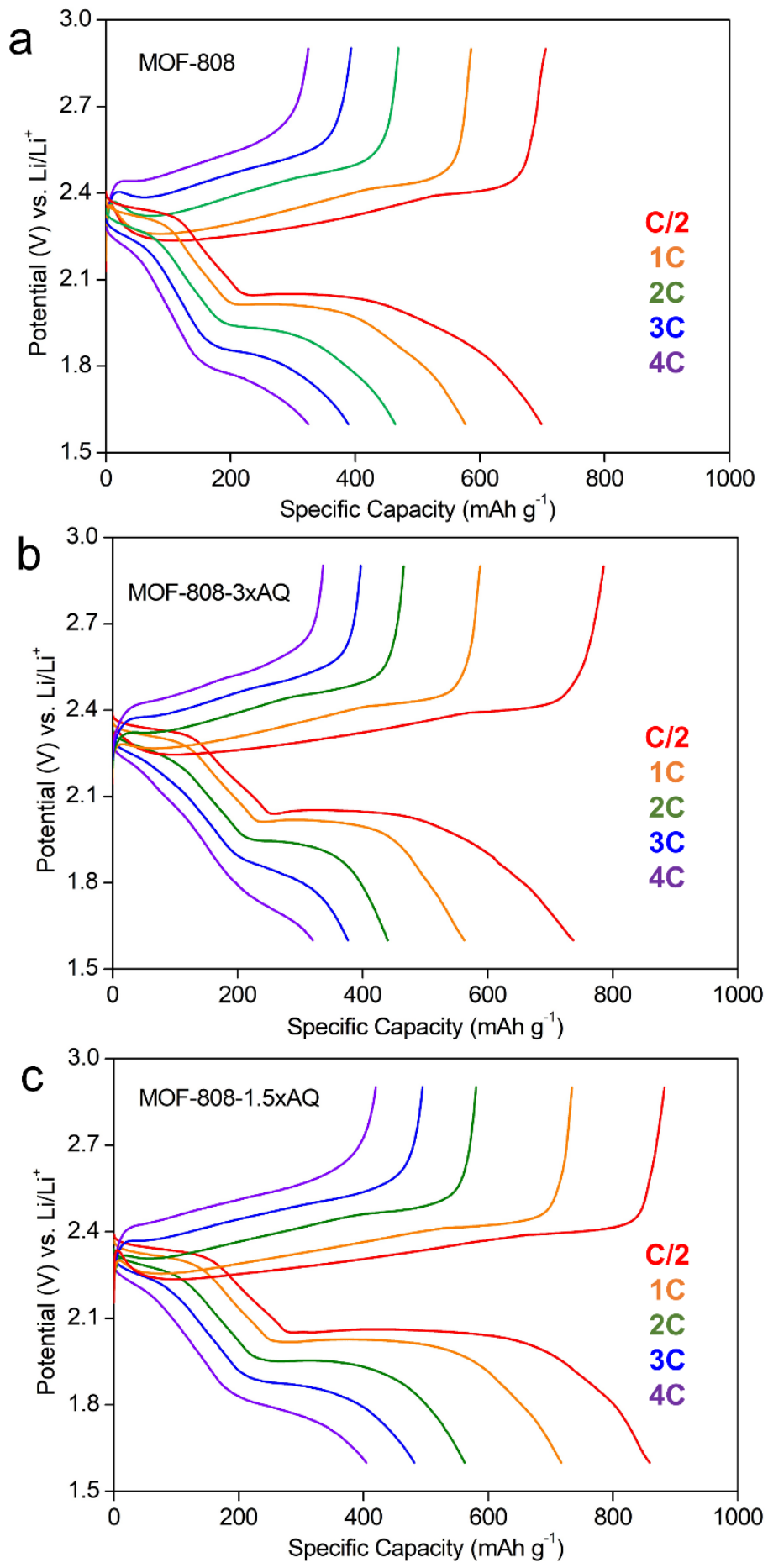

Figure S22. Galvanostatic charge-discharge profiles for (a) MOF-808, (b) MOF-808-3xAQ and (c) MOF-808-1.5xAQ at $\mathrm{C} / 2,1 \mathrm{C}, 2 \mathrm{C}, 3 \mathrm{C}$ and 4C. MOF-808-1.5xAQ composite cathode demonstrates more defined second plateau and less sloping curves. 

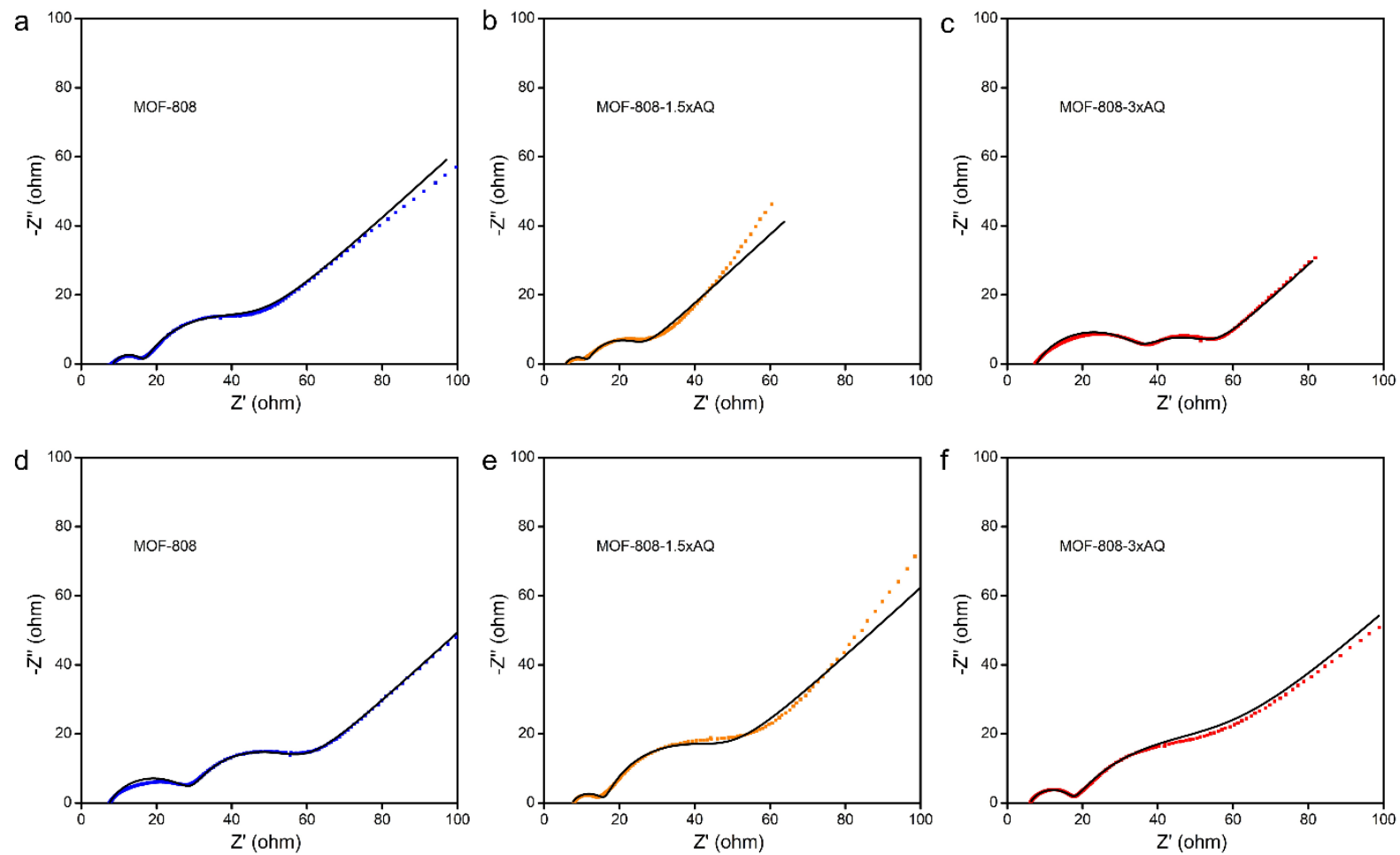

Figure S23. EIS results and fitting curves (black line) collected on coin cells (a-c) after 100 cycles at $\mathrm{C} / 2$ in the discharged state and (d-f) after rate capability test in the discharged state.

Table S6. EIS fitting results collected on coin cells in the discharged state (a) after 100 cycles at $\mathrm{C} / 2$ and (b) after rate capability test.

\begin{tabular}{|c|c|c|c|c|}
\hline & $\mathbf{R}_{\mathbf{1}}(\boldsymbol{\Omega})$ & $\mathbf{R}_{\mathbf{2}}(\boldsymbol{\Omega})$ & $\mathbf{R}_{\mathbf{3}}(\boldsymbol{\Omega})$ & $\mathbf{W} \times \mathbf{1 0}^{-\mathbf{2}}\left(\mathbf{\Omega} \mathbf{~ s}^{-1 / 2}\right)$ \\
\hline MOF-808 & 8.44 & 8.02 & 21.99 & 4.81 \\
\hline MOF-808-1.5xAQ & 5.69 & 5.84 & 11.09 & 6.32 \\
\hline MOF-808-3xAQ & 7.79 & 28.48 & 15.23 & 9.50 \\
\hline
\end{tabular}

b

\begin{tabular}{|c|c|c|c|c|}
\hline & $\mathbf{R}_{\mathbf{1}}(\boldsymbol{\Omega})$ & $\mathbf{R}_{\mathbf{2}}(\boldsymbol{\Omega})$ & $\mathbf{R}_{\mathbf{3}}(\boldsymbol{\Omega})$ & $\left.\mathbf{W} \mathbf{\times 1 0 ^ { - 2 }} \mathbf{\Omega}^{\mathbf{2}} \mathbf{~ s}^{-\mathbf{2}}\right)$ \\
\hline MOF-808 & 7.64 & 20.19 & 24.09 & 4.08 \\
\hline MOF-808-1.5xAQ & 7.48 & 8.06 & 22.46 & 2.99 \\
\hline MOF-808-3xAQ & 6.09 & 11.38 & 29.88 & 3.71 \\
\hline
\end{tabular}




\section{References}

(1) Liang, Y.; Hui, J. K. -H.; Yamada, T.; Kimizuka, N. Electrochemical Thermoelectric Conversion with Polysulfide as Redox Species. ChemSusChem 2019, 12 (17), 4014-4020. https://doi.org/10.1002/cssc.201901566.

(2) Bieker, G.; Diddens, D.; Kolek, M.; Borodin, O.; Winter, M.; Bieker, P.; Jalkanen, K. Cation-Dependent Electrochemistry of Polysulfides in Lithium and Magnesium Electrolyte Solutions. J. Phys. Chem. C 2018, 122 (38), 21770-21783.

https://doi.org/10.1021/acs.jpcc.8b06560. 